\title{
Gabriele Koziol
}

\section{Lizenzen als Kreditsicherheiten}

\author{
Zivilrechtliche Grundlagen in Deutschland, Österreich und Japan
}

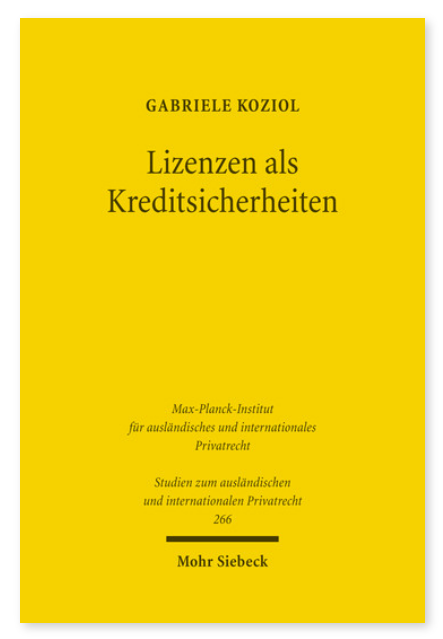

2011. XV, 179 Seiten. StudIPR 266

ISBN 978-3-16-151450-0

DOI 10.1628/978-3-16-151450-0

eBook PDF 59,00€

ISBN 978-3-16-150916-2

fadengeheftete Broschur 59,00€
Patente, Marken und Urheberrechte stellen wertvolle Vermögenswerte dar. Insbesondere für Unternehmen im Technologieoder Softwarebereich ergibt sich daraus das Bedürfnis, Immaterialgüterrechte sowie Nutzungsrechte an diesen als Sicherheiten für die Erlangung von Liquidität einzusetzen. Bei der Verwendung von Lizenzen als Kreditsicherheiten stellt sich zunächst die Frage, wie Lizenzen rechtlich einzuordnen sind. Ferner sind die Voraussetzungen für die Begründung von Sicherungsrechten an Lizenzen zu untersuchen. Prüfstein jedes Sicherungsmittels ist schließlich der Insolvenzfall, wobei nicht nur die Bestandfestigkeit des Sicherungsrechts zu erörtern ist, sondern auch das Schicksal der Lizenz selbst. Gabriele Koziol untersucht das bislang kaum behandelte Thema der Verwendung von Lizenzen als Kreditsicherheiten rechtsvergleichend für das deutsche, österreichische und japanische Recht, wobei sie sich um möglichste Einbindung in das allgemeine Zivilrecht bemüht.

Gabriele Koziol ist Professorin an der Universität Kyōto.
Jetzt bestellen:

https://mohrsiebeck.com/buch/lizenzen-als-kreditsicherheiten-9783161514500?no_cache=1

order@mohrsiebeck.com

Telefon: +49 (0)7071-923-17

Telefax: +49 (0)7071-51104 